Tesis 



\section{"El uso ilícito de la fuerza durante las protestas sociales y las violaciones a los derechos humanos. El caso peruano 2003-2011"}

\section{Sarita del Carmen Álvarez Reátegui}

En los últimos años, hemos sido testigos del aumento e intensidad de las protestas sociales en el mundo. Baste recordar el movimiento de los "indignados" o 15-M en España; las protestas en Egipto o en China; el movimiento Ocupa Wall Street, y las protestas de los estudiantes en Chile. Nuestro país no es ajeno a esta realidad, con un gran número de protestas sociales ${ }^{1}$ en los últimos años.

No existe una definición precisa, aquí o en el extranjero, de la protesta social. Por eso, la he definido como la manifestación colectiva de disconformidad de los ciudadanos que se dirige principalmente al Estado o a alguno de sus órganos debido a un hecho u omisión de algún ente estatal o no estatal, o de alguna persona, con la finalidad de ser escuchados y obtener respuesta a sus pedidos. La protesta social tiene su fundamento en el derecho a la libertad de expresión y de reunión.

En nuestro país, los altos índices de pobreza, la desigualdad en la distribución de la riqueza, la lentitud e ineficacia de los canales institucionales al alcance de la población para participar de las decisiones

1 No hay una cifra exacta sobre el número de protestas sociales que ocurren en el país, el que varía de acuerdo con la entidad que emita los datos. La Defensoría del Pueblo señala que entre enero de 2007 y setiembre de 2011 ha habido 2196 acciones de protesta. 
estatales y la falta de incidencia de la llamada "minoría mayoritaria" en las políticas públicas son las principales causas del surgimiento de las protestas sociales durante el periodo estudiado. Estas se han caracterizado por ser dispersas, explosivas y poco articuladas, limitándose a la búsqueda de resultados inmediatos (Remy, 2005, p. 19). Durante las protestas sociales, el Estado tiene el deber de respetar y garantizar la vigencia de los derechos humanos, el mantenimiento del orden interno y el orden público, así como el deber de garantizar la seguridad ciudadana. Los manifestantes han pasado de los clásicos plantones, movilizaciones, paros y huelgas, a formas violentas de protesta que se traducen en bloqueos de carreteras, enfrentamientos, tomas de locales y de rehenes. Ellos han encontrado en la protesta violenta una forma rápida de poner en agenda aquellos problemas que de otra manera no serían tomados en cuenta. Cuando la protesta excede los parámetros legales, tornándose violenta, afectando los derechos de terceros o el orden público, el Estado tiene la facultad de reprimirla, para lo cual cuenta con diversas medidas legales, como el arresto, la detención, la declaración del estado de emergencia y, de manera excepcional, el uso de la fuerza y de armas de fuego. La Policía Nacional es la encargada de restablecer el orden, y excepcionalmente lo hacen las Fuerzas Armadas.

Los encargados de hacer cumplir la ley, en el momento de usar la fuerza deben respetar los principios básicos de legalidad ${ }^{2}$, necesidad ${ }^{3} \mathrm{y}$ proporcionalidad $^{4}$, así como los estándares nacionales ${ }^{5}$ e internaciona-

2 Señala que los medios, métodos y demás actos usados por los encargados de hacer cumplir la ley deben ajustarse a las normas nacionales e internacionales que regulan el uso de la fuerza.

3 Establece que los encargados de hacer cumplir la ley solo harán uso de la fuerza cuando sea estrictamente necesario y en la medida necesaria para el desempeño de sus tareas.

4 Señala que debe haber un equilibrio entre el nivel de amenaza y el grado de fuerza empleada. La fuerza empleada debe ser lo menos lesiva para proteger el interés relevante.

5 Compuesto principalmente por el Manual de Derechos Humanos Aplicado a la Función Policial; la Directiva 01-2009-IN/0103.1, estableciendo procedimientos para garantizar el respeto de los derechos fundamentales de las personas (civiles y policías) en la dirección, organización y ejecución de las operaciones de control, mantenimiento y restablecimiento del orden público; y el Decreto Legislativo 1095, que establece reglas de empleo y uso de la fuerza por parte de las Fuerzas Armadas en el territorio nacional. 
les ${ }^{6}$ que regulan el uso de la fuerza. Sin embargo, la Policía, y en algunos casos las Fuerzas Armadas (FF.AA.), al intervenir para garantizar y restablecer el orden durante las protestas sociales en el periodo estudiado, desplegaron un grado de uso de la fuerza que en muchos casos no ha estado acorde con los principios básicos de legalidad, necesidad y proporcionalidad, ni con los estándares nacionales e internacionales que lo regulan. Además, en algunos casos, los policías reprimieron protestas lícitas y pacíficas. Este uso ilícito de la fuerza trajo como consecuencia un gran número de muertos, heridos, detenciones ilegales, afectaciones al debido proceso, entre otras violaciones a los derechos humanos.

A partir de lo indicado, el problema principal de la investigación es: ¿qué factores determinan el uso ilícito de la fuerza durante las protestas sociales en el Perú en los años 2003 a 2011? Y el problema secundario es: ¿qué derechos son afectados durante las protestas sociales como consecuencia del uso ilícito de la fuerza en ellas en los años 2003 a 2011?

En la presente investigación he podido establecer que los factores sociales, normativos e institucionales determinan que se haga un uso ilícito de la fuerza durante las protestas sociales en el Perú entre los años 2003 a 2011. En el factor social se encuentra la mentalidad represiva del Estado para enfrentar las protestas sociales, que tiende a castigar, antes que a prevenir; el factor normativo hace referencia a la falta de normas claras y de rango legal que regulen el uso de la fuerza; y el factor institucional desarrolla la falta de formación y capacitación de los miembros del orden en lo relacionado con el uso de la fuerza y los derechos humanos, la falta de entrenamiento específico y de armamento adecuado, así como las deficiencias en la planificación y ejecución de los operativos de restablecimiento y control del orden.

He podido determinar que durante el periodo estudiado se violaron principalmente el derecho a la vida (más de 39 personas perdieron la vida de manera arbitraria), la integridad personal (más de 286 personas resultaron heridas), la libertad y seguridad personal (hubo más de 231 detenciones arbitrarias), las garantías judiciales y la protección judicial (con afectaciones al debido proceso, como la falta de traductor o de representación por un abogado), así como los derechos a la libertad de expresión y reunión; mediante la represión violenta de protestas pacíficas y lícitas.

6 Contenidos en el Código de conducta para funcionarios encargados de hacer cumplir la ley y los principios básicos sobre el empleo de la fuerza y de armas de fuego por los funcionarios encargados de hacer cumplir la ley. 
La investigación se compone de cuatro capítulos.

El primero se ocupa de los aspectos generales de las protestas sociales, los deberes del Estado durante ellas, el marco normativo nacional e internacional que regula el uso de la fuerza, y la función de los encargados de hacer cumplir la ley (Policía Nacional y Fuerzas Armadas).

En el segundo capítulo se explican los factores sociales, normativos e institucionales que determinan que los encargados de hacer cumplir la ley hagan uso ilícito de la fuerza en las protestas sociales durante los años 2003-2011.

El tercer capítulo contiene un análisis de los hechos ocurridos durante la protesta social en Bagua el 5 de junio de 2009, a partir del cual se observan las lamentables consecuencias de un operativo realizado a última hora y que no se ajustó a las normas que regulan el uso de la fuerza.

En el cuarto capítulo se establecen los principales derechos humanos afectados como consecuencia del uso ilícito de la fuerza y la responsabilidad internacional del Estado por las violaciones a los derechos humanos.

\section{Conclusiones}

1. El Estado, frente a las protestas sociales y especialmente las de carácter violento, asume un rol represivo dando prioridad al uso de la fuerza e incluso de armamento letal contra los manifestantes; también da una mayor participación a las Fuerzas Armadas en el control del orden interno. Es necesario evitar toda forma de criminalización de la protesta social. El diálogo, la discusión pública y la búsqueda de consensos son las mejores herramientas para evitar el surgimiento de las protestas sociales.

2.- El Decreto Legislativo 1095, que establece reglas de empleo y uso de la fuerza por parte de las Fuerzas Armadas en el territorio nacional, da una definición amplia de "grupo hostil", de manera que se podría permitir la realización de operaciones militares contra manifestantes violentos, siendo ellas válidas en el marco del derecho internacional humanitario, derecho que no se aplica a las protestas sociales violentas porque son consideradas casos de violencia interna a los que se les aplican las normas del derecho internacional de los derechos humanos. Además, en su artículo 4, inciso 3, permite la actuación de las Fuerzas Armadas en escenarios internos sin que medie declaración del estado de emergencia, lo que considero es inconstitucional debido a que esa 
actuación, en esos escenarios, es excepcional. Además, de acuerdo con el principio de corrección funcional, la Policía Nacional del Perú es la encargada del mantenimiento y restablecimiento del orden y cuenta con una preparación especial, muy diferente a la de las Fuerzas Armadas, que se encargan de la defensa nacional y su preparación está dirigida al enemigo.

3.- El desconocimiento de la legislación, y la deficiente formación y capacitación en materia del uso de la fuerza y derechos humanos por parte del personal policial y el de las Fuerzas Armadas, trajeron como consecuencia que en el momento de restablecer el orden no actuaran de acuerdo con las normas que regulan el uso de la fuerza. Además, la falta de armamento disuasivo de los efectivos policiales y de los miembros de las Fuerzas Armadas no ha permito que puedan hacer un uso progresivo y diferenciado de la fuerza en el momento de intervenir en escenarios de alta conflictividad, ante multitudes. Cabe resaltar que el armamento y los equipos de comunicaciones son obsoletos y se encuentran en mal estado.

4.- Los encargados de hacer cumplir la ley no elaboran ni ejecutan un plan operativo que se ajuste a las normas institucionales; por el contrario, sus intervenciones se han caracterizado por no realizar un planeamiento ni una apreciación de inteligencia actualizada.

\section{Referencias}

Remy S., María Isabel (2005). Los múltiples campos de la participación ciudadana en el Perú: Un reconocimiento del terreno y algunas reflexiones. Lima: Instituto de Estudios Peruanos. 
